\title{
5
}

\section{Nitrate Assimilation: The Role of In Vitro Nitrate Reductase Assay as Nutritional Predictor}

\author{
Fungyi Chow \\ University of Sao Paulo, Department of Botany, Institute of Bioscience \\ São Paulo, SP \\ Brazil
}

\section{Introduction}

Macroalgae or macrophytes are a heterogeneous assemblage of macroscopic eukaryotes belonging to various evolutionary lineages, which live predominantly in aquatic habitats. They have undifferentiated vegetative bodies organized in pseudoparanchymatous and parenchymatous bodies. As with higher plants, marine macroalgae or seaweeds are photosynthetic species that, by harvesting sunlight energy, convert carbon dioxide in oxygen to produce organic compounds, especially carbohydrates. In addition, they require mineral nutrients, essential for growth, development and reproduction, which are incorporated into carbon skeletons.

In natural aquatic ecosystems, $95 \%$ of the nitrogen which occurs as dissolved dinitrogen gas $\left(\mathrm{N}_{2}\right)$, is not directly accessible to most photosynthetic-oxygen organisms. Dissolved inorganic nitrogen (DIN) includes the ions, ammonium $\left(\mathrm{NH}_{4}^{+}\right)$, nitrite $\left(\mathrm{NO}_{2}^{-}\right)$, and nitrate $\left(\mathrm{NO}_{3}^{-}\right)$. In seawater, and under natural conditions, about 3,5\% is $\mathrm{NO}_{3}^{-}\left(\mathrm{ca} .0 .35 \mathrm{mg} \mathrm{NO} 3^{-} \cdot \mathrm{L}^{-1}\right)$, which, near to coastal zones, appears in abundance as a product of upwelling or pollution, whence, their importance as the predominant cause of local eutrophication.

Thus, nitrate constitutes the prevailing available nitrogen source for macroalgae in the marine environment. The available DIN may be supplemented by dissolved organic nitrogen (DON), this including urea and amino acids. For all eukaryotic photoautotrophs, $\mathrm{NH}_{4}{ }^{+}, \mathrm{NO}_{2}-$, and $\mathrm{NO}_{3}{ }^{-}$are the only directly assimilated sources.

Nitrogen, which is rapidly taken up, is a key element in several compounds present in the cells. It is used to build up amino acids, proteins, nucleoside phosphates, nucleic acids, and other organic N-containing macromolecules. The availability of nutrients, especially nitrogen, in marine habitats is one of the main regulating factors that limit growth, morphology, development, reproduction, distribution, and biochemical composition in seaweeds. The importance of nitrogen for biological life is evident, in that only oxygen, carbon, and hydrogen are more abundant in the cells of photosynthetic organisms.

Macroalgae and photoautotrophic organisms have considerable intracellular capacity for storing nitrogen as soluble nitrogen and organic molecules, whereby growth and development can be regulated and limited according to nitrogen uptake. This characteristic for storing and assimilating nutrients, when available and at high concentrations, besides 
facilitating their use under external, restrictive conditions, provides certain species with ecological advantages for persistence and prolife during limiting stress periods.

Seasonal nutrient limitation in macroalgal growth is well known (Lobban \& Harrison, 1994). The importance of nitrogen for the growth-cycle is related to life-strategy. In perennial species, nutrient availability is a determinant factor that plays an important role in the seasonal reproductive life-cycle (Kain, 1989). In annual species, nitrogen, when available, is uptake and stored inside the cells, whence its rapid conversion into new biomass.

During the past decades, substantial efforts have been made to understand the biochemistry, molecular biology and regulation of nitrate reductase (NR) in higher plants, to so further ecophysiological information and applied botany. The basic-action mechanisms and importance of NR in seaweeds are no different from higher plants. Notwithstanding, the amount of knowledge is still superficial and phycological studies scarce.

Based on higher plants and microalgae, the purpose is to briefly point out the role of NR in nitrogen metabolism, with a focus on macroalga research, and highlight the importance of in vitro NR assay optimization and its value as a physiological tool.

\section{Overview of nitrate assimilation}

Inorganic nitrogen availability plays a critical role in the physiology of marine macroalgae and the productivity of complete ecosystems (Lapointe \& Duke, 1984). Nitrogen depletion has been shown to increase photoinhibitory responses in the photosynthesis of marine organisms, including macroalgae (Korbee-Peinado et al., 2004; Huovinen et al., 2006). On the other hand, photosynthetic pigments, through generally being positively correlated with nitrogen availability, rapidly respond to varying nitrogen levels (Davison et al., 2007). For example, phycobiliproteins, reported as nitrogen-storage compounds in N-rich conditions, act as nitrogen sources under N-limiting conditions (Lobban et al., 1985).

Much of what is known on nitrogen metabolism is based on studies with microalgae; the number with macroalgae is still few in comparison.

As nitrogen uptake by macroalgae are usually studied by monitoring the disappearance of the nutrient from the culture medium and is influenced by irradiance, temperature, water motion, desiccation, and age.

Macroalgae have either the plasticity or preference to uptake several forms of nitrogen. Hanisak (1983) noted that the uptake rate of ammonium generally exceeds that of nitrate. Chow et al. (2001) registered the same trend for Gracilaria chilensis, with total uptake of only ammonium, when present together with nitrate and nitrite. However, very high concentrations of ammonium $(>30-50 \mu \mathrm{M})$ can saturate nitrate transport, thereby inducing toxification by ammonium. As ammonium can be used directly to synthesize amino acids, and nitrate stored inside vacuoles, the energetic cost of ammonium assimilation is lower than that of nitrate.

Nitrate uptake normally involves saturating kinetics (DeBoer, 1981). As greater concentrations of intracellular nitrate than that of the surrounding seawater constitute a negative gradient for transport, active transport can be considered as a primary process. Some authors have proposed that the NR plasma membrane acts as protein transporter to within the cell.

Considering the relative abundance of environmental nitrate in seawater, the nitrogen metabolism is usually commanded by nitrate assimilation fitness. Nitrate $\left(\mathrm{NO}_{3}^{-}\right)$is taken up 
by the cells and translocated across the plasmalemma by energy-dependent processes. Once inside the cells, any excess can be stored within vacuoles, while a fraction is being metabolized in the cytoplasm by reduction to nitrite, via the enzyme nitrate reductase (NR), and using $\mathrm{NAD}(\mathrm{P}) \mathrm{H}$ as electron donor. In turn nitrite $\left(\mathrm{NO}_{2}{ }^{-}\right)$is transported to chloroplasts and reduced to ammonium, prior to assimilation into organic compounds by enzyme nitrite reductase $(\mathbf{N i R})$, by means of reduced ferredoxin $\left(\mathrm{Fd}_{\mathrm{red}}\right)$ as electron source. Thus, the nitrogen assimilation pathway is a two-step process, first with $\mathrm{NO}_{3}^{-}$reduction to $\mathrm{NO}_{2}^{-}$(1) and then to ammonium $\left(\mathrm{NH}_{4}^{+}\right)(2)$ as described below:

$$
\begin{gathered}
\text { Nitrate reductase (NR) } \\
\mathrm{NO}_{3^{-}}+\mathrm{NAD}(\mathrm{P}) \mathrm{H}+2 \mathrm{e}^{-}+\mathrm{H}^{+} \rightarrow \mathrm{NO}_{2^{-}}+\mathrm{NAD}(\mathrm{P})^{+}+\mathrm{H}_{2} \mathrm{O} \\
\quad \text { Nitrite reductase (NiR) } \\
\mathrm{NO}_{2}^{-}+6 \mathrm{Fd}_{\text {red }}+6 \mathrm{e}^{-}+8 \mathrm{H}^{+} \rightarrow \mathrm{NH}_{4}^{+}+6 \mathrm{Fd}_{\mathrm{ox}}+2 \mathrm{H}_{2} \mathrm{O}
\end{gathered}
$$

Nitrite and ammonium ions can not be accumulating inside cells, as they are cytotoxic through producing $\mathrm{pH}$ change and inducing reactive nitrogen species (RNS) and oxidative damage. Consequently, their incorporation into organic compounds must be relatively fast, in order to prevent accumulation and toxicity. In the case of photosynthetic organisms, fungi, and bacteria present a variety of mechanisms to regulate and control the expression of those enzymatic activities involved in nitrogen assimilatory pathways.

The assimilation of ammonia- $\mathrm{N}$ into carbon compounds (amino acids) primarily takes place through the sequential actions of glutamine synthetase (GS) and glutamine 2-oxoglutarate aminotransferase (GOGAT), inside chloroplasts, where both are localized, although isozymes of both may also be found in cytosol. Ammonium assimilation by GS requires glutamate (Glu) as substrate and ATP input to form glutamine (Gln) (3).

\section{Glutamine synthetase (GS)}

$$
\mathrm{NH}_{4}{ }^{+}+\text {glutamate }(\mathrm{Glu})+\mathrm{ATP} \rightarrow \text { glutamine }(\mathrm{Gln})+\mathrm{ADP}+\mathrm{Pi}
$$

The amino-N of glutamine, subsequently transferred to 2-oxoglutarate (2-OXG), is reduced by GOGAT to form two molecules of glutamate (4).

\section{Glutamine 2-oxoglutarate aminotransferase (GOGAT)}

$$
\text { 2-oxoglutarate + glutamine }(\mathrm{Gln})+\mathrm{NADPH} \rightarrow 2 \text { [glutamate] }(\mathrm{Glu})+\mathrm{NADP}^{+}
$$

The production of glutamate can be through two pathways. The first involves the reductive amination of $\alpha$-ketoglutarate catalyzed by the enzyme glutamate dehydrogenase (GDH), which is found in chloroplasts and mitochondria. In the latter, $\alpha$-ketoglutarate is normally continually produced by the Krebs cycle.

Independent of the location of GS and GOGAT, glutamate is exported from chloroplasts to cytosols, where transamination reactions can proceed, thereby facilitating the synthesis of other amino acids.

The control of the nitrate assimilatory rate is attributed to NR action, as this is the first enzyme in the specific pathway. Consequently, it is of increasing interest to study its 
molecular and catalytic properties, as well as the physiological responses to environmental stressing conditions and intracellular factors. Nitrate reductase activity has been proposed as an index of the rate of nitrate incorporation, with the additional inference that nitrate reduction is a rate limiting process for nitrogen assimilation, since any reduction in enzymatic activity results in a relative drop in nitrogen assimilation.

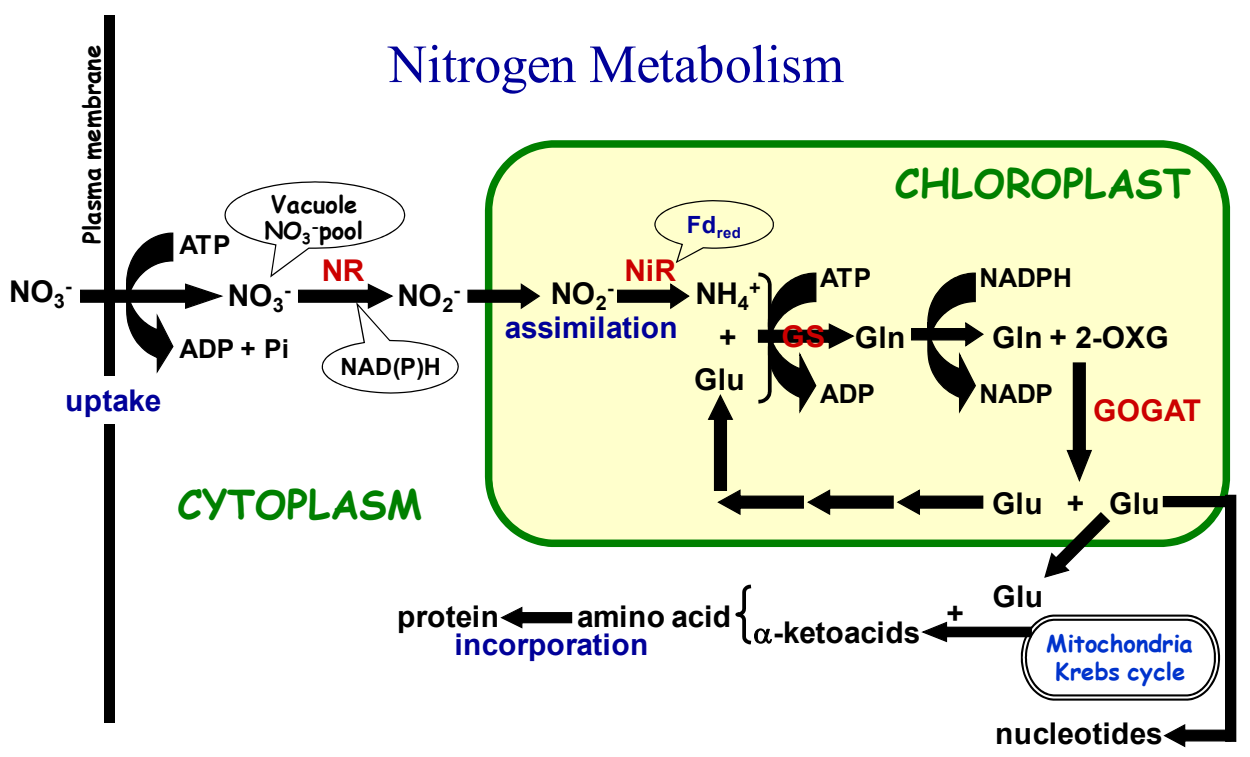

Fig. 1. General brief of nitrate assimilation pathway. Nitrate $\left(\mathrm{NO}_{3}{ }^{-}\right)$is actively transported from the external medium across the plasma membrane into the cytoplasm. It can be stored into vacuoles or reduced to incorporating in carbon skeletons. Nitrate is reduced to nitrite $\left(\mathrm{NO}_{2}^{-}\right)$in the cytoplasm by nitrate reductase $(\mathrm{NR})$ that uses $\mathrm{NAD}(\mathrm{P}) \mathrm{H}$. Nitrite is transported inside the chloroplast and reduced to ammonium $\left(\mathrm{NH}_{4}^{+}\right)$by nitrite reductase $(\mathrm{NiR})$ that uses reduced ferredoxin $\left(\mathrm{Fd}_{\mathrm{red}}\right)$. Ammonium is incorporated into glutamate $(\mathrm{Glu})$ to form glutamine (Gln) via the action of glutamine synthetase (GS). The amino-N of Gln is then transferred to 2-oxoglutarate (2-OXG) via the action of glutamine 2-oxoglutarate aminotransferase (GOGAT). This reaction produces two molecules of Glu, one of them reenters to the assimilation pathway as substrate for GS and the second molecule of Glu is exported to the cytoplasm and will participate of transamination reactions with a-ketoacids to produces other amino acids and proteins (modified from Falkowski \& Raven, 1997).

\section{Interaction between nitrate assimilation and carbon metabolism}

Nitrate assimilation is intrinsically dependent on the organic carbon substrates, reductants, and ATPs that are supplied for both processes photosynthesis and respiratory processes (Turpin, 1991). When nitrogen is limited, or photosynthesis and respiration are negatively affected, this dependency becomes multifactorial, whereupon compensatory mechanisms or regulation must be activated. 
It is clearly evident that nitrogen metabolism in macroalgae is closely linked to photosynthetic carbon metabolism (Vergara et al., 1998). Nitrate reductase activity presents maximal enzymatic rates during the diurnal phase, and minimal during dark phase, with a narrow relationship of maximal and minimal photosynthetic rates. These responses indicate regulatory activation of both processes by light. The intracellular toxic conditions of nitrite and ammonium make the urgent incorporation of both into the carbon skeleton essential, to so avoid toxicity.

Carbon molecules and reductant sources proceeding from photosynthesis, is an indication of the existence of related regulatory mechanisms between both processes. Carbon and nitrogen metabolic pathways consume large amounts of photosynthetic carbon and energy sources. Both metabolic forms are connected, either by the organic carbon and energy that are directly supplied for photosynthetic electron transport and fixated $\mathrm{CO}_{2}$, or by the respiration of fixed carbon, via glycolysis by the Krebs cycle, and the electron transport chain of mitochondria. Therefore, the integration of these important metabolic processes must have integrated regulatory mechanisms.

Nitrogen limitation affects photosynthetic processes. Under N-limiting conditions, there is a concomitant decrease in PSII photochemical efficiency, as a consequence of the dissipation of absorbed excitation energy in the center of pigments. Depleted photosynthetic efficiency appears to occur through a drop in the number of functional PSII reaction centers relative to the antennae system (Falkowski, 1992). On the other hand, the reduction in photosynthetic energy conversion under N-limiting conditions appears to affect amino acid biosynthetic processes. Nitrogen limitation also affects the respiration rate. The molecular basis of nitrogen limitation and respiratory rate alteration is unclear, but it appears to be related to the demand for carbon skeletons and ATP, two of the major products of respiratory pathways. Thus, the depletion of nitrogen creates a chain reaction that decompensates energy metabolism and amino acid biosynthesis, thereby affecting photosynthesis, respiration and growth.

\section{Nitrate reductase in macroalgae}

Nitrate reductase, a relatively large molecule, is usually composed of two or four subunits, each of which with approximately $100 \mathrm{kDa}$. Nakamura \& Ikawa (1993) reported these subunits in Porphyra yezoensis at close to $100 \mathrm{kDa}$. The four in Gracilaria tenuistipitata var. liui (Lopes et al., 2002), were also of the same size, as were the possibly two in Kappaphycus alvarezii (Granbom et al., 2007).

Three assimilatory NR forms are recognized in eukaryotes: (a) EC 1.6.6.1 NADH-specific and (b) EC 1.6.6.2 NADP/NADPH, both occurring in eukaryotic algae and higher plants, and (c) EC 1.6.6.3 NADPH-specific.

The enzyme is preferentially present in the cytoplasm, although there is growing evidence of NR associated to chloroplast membranes (Solomonson \& Barber, 1990) and plasmalemma (Tischner et al., 1989; Fernandez-Lopez et al., 1996).

Nitrate reductase becomes interesting through its usefulness as a model for prospecting multi-component interaction mechanisms related to redox enzymes. Nitrate reductase is one of the few inducible/repressible enzymatic systems reasonably well-characterized in photoautotrophs, especially in higher plants and microalgae, thus making it a fantastic biological model for physiological studies. On the other hand, it is of concern to use NR as an ecophysiological parameter for predicting nutritional rates of nitrate assimilation and 
growth. Furthermore, as NR-protein characteristics differ among algal groups, this diversity may be of relevance in revealing evolutionary adaptation patterns (Zhou \& Kleinhofs, 1996; Howartha \& Baumb, 2002; Stolz \& Basu, 2002).

Marine macrophytes inhabiting intertidal coastal regions are exposed to extreme fluctuations in physicochemical parameters, midday increased irradiance levels, UV radiation (UVR), nitrogen depletion, desiccation, high-temperature stress, etc. (Lobban et al., 1985). Individually or together these stressing conditions result in drastic physiological responses and acclimation. Thus, comprehension of macroalgal responses to daily and seasonal fluctuations in these abiotic factors is critical for a better understanding of the regulation of nitrogen metabolism.

Nitrate reductase-activity assaying has been used for indicating algal capacity in using nitrate and the internal nutritional index. A newer approach is to determine the protein at the molecular level by studies of gene NR-mRNA expression.

The use of NR in an ecological context is particularly relevant for marine environments where nitrogen is often limiting, thereby providing relevant information regarding the physiological nitrogen status of organisms (Hernández et al., 1993).

Nitrate reductase is considered as a key enzyme in nitrogen metabolism, through being, not only the rate-limiting enzyme in inorganic nitrogen assimilation, but also the major regulatory step in nitrogen metabolism (Crawford, 1995; Berges, 1997; Davison \& Stewart, 1984; Lartigue \& Sherman, 2005; Young et al., 2009). Changes in NR activity, both in the field or in laboratory, have been examined in very few macroalgae.

Nitrate reductase expression is a complex process regulated by various factors, such as levels of nitrate, CO2, light, carbon skeletons and nitrogen metabolites (Crawford, 1995, Lopes et al., 2002). Furthermore, it is highly regulated in multiple steps, transcriptionally, post-transcriptionally, translationally and post-translationally. These regulatory mechanisms can act individually or synergically, and are correlated to short and long-term NR response. Thus, NR activity can be modified rapidly in response to nitrate availability and other controlling factors.

This intricate control can be shown experimentally by adding nitrate to the medium. In Gracilaria chilensis, NR activity was thus rapidly stimulated within a few minutes (Chow et al., 2007; Chow \& Oliveira, 2008), probably by post-translational NR-protein regulation. Lartigue \& Sherman (2005) observed the same trend in Enteromorpha sp. A like inducing response, under the same conditions, has also been observed in other macroalgae (Gao, Smith \& Alberte 1995; Lartigue \& Sherman, 2005; Young et al., 2007; Martins et al., 2009; Cabello-Pasini et al., 2011).

Nitrate reductase activity in Arctic species appears to be directly enhanced by nitrate addition, with relatively little feedback from the N-status of the cell (Gordillo et al., 2006). Communities of Laminariales species apparently possess a high degree of resilience to disruption in natural nutrient-availability patterns.

Inactivation of NR activity and degradation of NR-protein have been observed in microalgae, macroalgae and higher plants undergoing nitrate deficiency or other forms of reduced nitrogen (e.g. ammonium and urea) (Weidner \& Kiefer, 1981; Vergara et al., 1998; Solomonson \& Barber, 1990; Balandin \& Aparicio, 1992; Crawford \&Arst, 1993; Berges et al., 1995; Vergara et al., 1998; Campbell, 1999; Gao et al., 2000; Chow \& Oliveira, 2007; Nicodemus et al., 2008). The NR-inhibiting action mechanism is unknown, although it is thought to occur via feedback-regulation of ammonium assimilation by metabolites, e.g. glutamine (Flynn 1991, Vergara et al., 1998), or indirectly by inhibition of nitrate-uptake (Collos, 1989). 
Synthesis of the NR protein is also regulated by its substrate with a half-life of a few hours. The induction of NR activity is preceded by an increase in NR mRNA, which is activated in a question of hours (Granbom et al., 2007).

Light is a regulatory factor of nitrogen metabolism. Light provides the energy to produce/reduce the power and ATP utilized in nitrate transport, nitrate and nitrite reduction and ammonium fixation into amino acids. Furthermore, light increases the production of carbon skeletons essential for nitrogen assimilation. Additionally, light may play a signaling role in controlling the activity-level and NR-protein synthesis.

As NR-protein degradation normally takes a few hours, near to the interphase light:dark cycle, NR is rapidly regulated by phosphorylation and dephosphorylation mechanisms. Transient induction of NR activity in G. chilensis by light pulse, during the dark phase, was inhibited by the addition of calyculin A (Chow et al., 2008), thereby inferring this rapid NR regulation, as already reported in higher plants (Kaiser \& Spill, 1991; Huber et al., 1992a, b; Kaiser \& Huber, 1994; Campbell, 1996).

Probably the quick-NR regulatory mechanisms by phosphorylation and dephosphorylation constitute an essential system for tolerating changes in environmental stress, especially for macroalgae, which undergo tidal variation that affects nutrient availability and irradiance intensity. Under permanent stressing-conditions on a scale of hours to weeks, the synthesis and degradation of NR proteins and mRNA would be the most functional mechanism in preventing unnecessary energy expenditure.

Nitrate reductase is also influenced by irradiance (Davison \& Stewart, 1984; Gao et al., 1995; Lopes et al., 1997; Vergara et al., 1998; Lartigue \& Sherman, 2002; Chow \& Oliveira, 2008), the rapid suppression in darkness probably arising from the availability of carbon skeletons, $\mathrm{ATP}$, and $\mathrm{NAD}(\mathrm{P}) \mathrm{H}$ from photosynthesis and respiration.

Ultraviolet radiation also affects NR activity in macroalgae (Figueroa \& Viñegla, 2001). Nevertheless, studies are scarce, and the mechanisms of action unknown.

NR and NR-protein activities manifest a daily rhythm with circadian influence (Lillo, 1983; Deng et al., 1991; Lopes et al., 1997, 2002; Granbom et al., 2004, 2007; Chow et al., 2004, 2007; Granbom et al., 2007). Under the light:dark cycle, NR activity reaches a plateau around the middle of the photoperiod, as well as a nocturnal minimum (Weidner and Kiefer 1981, Gao et al. 1992, Ramalho et al. 1995, Lopes et al. 1997, Chow et al. 2004, 2007; Granbom et al. 2004), presumably the normal behavior in photosynthetic species.. The circadian diel cycle of NR seems to be primarily regulated transcriptionally and correlated to the rate of mRNA protein-synthesis (Smith et al., 1992; Ramalho et al., 1995; Granbom et al., 2007). The peaks of enzymatic activity appear to be in concert with maximal photosynthetic flow, when intracellular carbohydrates and end products of photosynthesis begin to accumulate. At this point, the importance of light in promoting NR activity and synthesis is indirectly linked to carbon metabolic requirements.

Low NR activities during darkness have been suppressed by the artificial apply of lightmimicry carbohydrate sources. Furthermore, a light-pulse of 15 minutes during the dark phase, also induced NR activity to levels similar to those of the light phase in G. chilensis (Chow \& Oliveira, 2008), possibly indicating NR inducible behavior by post-translational mechanisms. When intracellular carbohydrates begin to accumulate in excess, NR mRNA transcription is suspended. Inversely, when carbohydrates become depleted, NR expression is enhanced. 
Higher NR activities are also associated with parts with active metabolic rates, and probably, to high levels of photosynthetic activity. In macroalgae with apical growth, NR activity in the tips is higher than in the basal parts (Granbom et al., 2004, 2007; Chow, 2004), thereby implying post-translational regulation. Nevertheless, NR protein content in the basal parts is the highest (Granbom et al., 2007), possibly indicating that a large part of NR is in an active form, compared to the basal part of the thallus.

Post-translational regulatory mechanisms are common in NR enzymes, especially during short-term response. This mechanism includes phosphorylation (Huber et al., 1992) involving specific protein kinases, protein phosphatases and a protein inativator (MacKintosh et al., 1995; Glaab \& Kaiser, 1996).

In most studies of macroalgae NR activity, it is possible to establish the same trend of physiological response, i.e., the pronounced dependence on the external and internal pool of available nitrate, light stimulation and low or constitutive dark activity, temperature range of action according to the natural habitat of the seaweed, and correlations with carbon and ATP availability from photosynthesis and respiration. The slight differences in NR behavior can be attributed to species-specific response depending on particular environmental conditions, and may reflect special turnover of NR activity, as a product of acclimation and adaptation response to the extremely changeable intertidal environment.

\section{In vitro nitrate reductase assay (optimization)}

For several years, we have been studying the physiology of the red macroalgae, gracilariods (Rhodophyta, Gracilariales), from different view-points. In most cases, these have been cultured in PES (Provasoli Enrichment Medium) and VSES (von Stosch Enrichment Solution), at different concentrations and biomass densities.

Nitrogen repletion and starvation causes, not only alterations in pigment content, nitrogen assimilation and photosynthesis, but also morphological changes in growth and ultrastructure. Consequently, certain studies in our laboratory were directed towards characterizing and understanding nitrogen assimilation regulation, especially as regards NR behavior. Undoubtedly, physiological changes in nitrate assimilation and NR activity are involved during alga growth and development. Knowledge of these responses would contribute towards a better optimization of laboratory efforts and in-field cultures for physiological studies and biomass yield, for possible economical usage.

Methods for estimating in vitro NR activity have been developed by Weidner \& Kiefer (1981), Chapman \& Harrison (1988), Thomas \& Harrison (1988), Brinkhuis et al. (1989) and Chow et al. (2001). Assaying procedures of NR activity are based on quantifying the reduction rate of nitrate to nitrite during the reaction catalyzed by intracellular NR enzymes.

Enzymatic NR assays have been used without considering adequate optimization of the method. The low NR activity observed during assaying could be due to the loss of enzymatic cofactors during extraction, inhibition of activity by phenolic compounds or other inhibitors, and the presence of endogenous proteases. The key points in NR assaying depend on adequate enzyme extraction, preservation, and stability during the whole procedure. There are two important considerations in enzymatic assays: (a) the enzyme must to be completely or nearly completely extracted, and (b) assaying conditions, such as $\mathrm{pH}$, temperature, substrate and electron donor concentrations, and protectant, must be optimal for maximal activity, in order to preserve enzymatic activity during the process. In 
most cases, NR activity is measured by saturating the enzymatic system with substrate. Under saturation conditions, NR activity is used as a nutritional estimator of nitrogen metabolism capacity. Some researchers prefer to use in vitro NR data as "potential activity", this representing a theoretical maximum of real NR activity.

Furthermore, the amount of detectable NR activity depends on protocol optimization, since enzymatic activities can vary between and within species, according to environmental conditions, circadian fluctuation and endogenous nutritional status, as well as thallus portion, age and size. Thus, for reliable comparison and evaluation, it is important to optimize the enzymatic assay, and clearly establish the conditions of the biological material to be studied.

Nitrate redutase assay is based on defining, spectrophotometrically, nitrite concentrations of the product from nitrate substrate reduction by the NR enzyme at constant temperature and time (Eppley et al., 1969). Spectrophotometric in vitro NR assay, while relatively easy and fast, and conferring the advantage of kinetic dependence between activity and time, confirmable by quantification of nitrate reduction, is not sensitive to any enzymatically crude extract. Nevertheless, it is recommended for very active and induced extracts. The comparison between deficient $\mathrm{N}$ samples cannot be sensitive enough. Therefore, even for studies of limited $\mathrm{N}$, it is recommended to supply nitrate before sampling, to thus guarantee NR induction during the assay.

Appropriate extraction of the complete NR enzyme for in vitro assaying was achieved by grinding the biological material in liquid nitrogen. Sample grinding under liquid nitrogen increases cell disruption, thus facilitating the extraction of larger amounts of NR enzymes. The addition of bovine serum albumin (BSA) is advisable for protection against proteolytic enzymes or phenolic compounds, although additional protectants must be used in the case of complex species, so as to avoid enzyme denaturation by proteases, or phenolic and other compounds (e.g. high phenolic-containing brown algae). Another precaution for preserving enzymatic activity is to maintain the crude extract at a low temperature $\left(4^{\circ} \mathrm{C}\right.$ or on ice), and protected from light, to so prevent activity-degradation until assaying.

In vitro assays require fixed conditions, as regards $\mathrm{pH}$, temperature, and the concentration of substrate and reductant source, as well as strict testing of each parameter of all the biological material to be studied. Macroalgal $\mathrm{pH}$ assaying varies slightly between species, maximal activity having been observed close to pH 8.0 (Lopes et al., 1997; Chow et al., 2004, 2007; Granbom et al., 2004).

Nitrate reductase activity is temperature sensitive over a narrow range, with several optimum temperatures for the various species, depending on the habitat. For temperate macroalgae, this ranges from 10 to $25^{\circ} \mathrm{C}$ (Gao et al., 2000; Berges et al., 2002; Chow et al., 2004). Activities at low temperatures may require a larger amount of NR protein or higher catalytic rates to so maintain the same catalytic activity, as during low winter temperatures enzymes function below the optimum. Species with high NR activity during the winter may present a cold acclimation component. This high activity has been reported in Laminaria saccharina (Davison \& Davison 1987), Fucus vesiculosus (Collén \& Davison 2001), and L. digitata, Fucus serratus, Fucus vesiculosus and Fucus spiralis (Young et al. (2007). Macroalgae in tropical and sub-tropical environments presented high temperature tolerance during assaying (Lopes et al., 1997; Chow et al., 2007; Granbom et al., 2004; Martins et al., 2009), the optimum usually being higher than normal.

Nitrate reductase activity can also vary considerably among and within species, depending on natural or laboratory growing conditions. Therefore, optimal concentrations of electron 
donor $(\mathrm{NAD}(\mathrm{P}) \mathrm{H})$ and substrate must be verified for each of the species studied, to so guarantee saturating conditions for assaying.

As nitrate reductase activity is daily cyclical, this requires care with the period of collecting samples, since differences among treatments can arise from natural circadian behavior, and not from treatment effects. Furthermore, NR is more active in areas with highly active metabolic rates, usually the meristematic region. For example, Granbom et al. $(2004,2007)$ and Chow (2004) detected higher NR activity in apical than basal parts in Kappaphycus alvarezii and G. chilensis, respectively. Thus, the appropriate choice of biological material for enzymatic assaying is also extremely important, as the amount of extractable enzyme varies drastically among and within species, with thallus part and age, internal nutritional stock, environmental nitrogen availability, culture conditions, etc.

Optimized in vitro NR activity in some macroalgae was studied and important highlights described (Lopes et al., 1997; Lartigue \& Sherman, 2002; Chow et al., 2004, 2007; Granbom et al., 2004).

There is a growing interest in applying macroalga NR activity to evaluating nutritional physiology in the laboratory and field, as a useful ecophysiological index. On the other hand, NR is regarded as a focal point in regulating the nitrogen assimilation pathway and for integrating the control of carbon and nitrogen metabolism. However, the potential applicability of in vitro NR assaying, as an important parameter of $\mathrm{N}$ and $\mathrm{C}$ metabolism, must to be carefully considered, in which case optimal assaying procedures are required.

\section{Important remarks}

In general, the importance of nitrogen metabolism in the marine environment, particularly nitrate assimilation, is based on the frequent identification of nitrogen as limiting nutrients for macroalgal growth. Various species under the same environmental conditions have developed special strategies for remaining in the habitat and benefit from the adversity of nitrogen limitation, either by taking advantage of nitrogen pulses or learning to live with low nutrient levels.

On the other hand, the increasing eutrophication of coastal aquatic environments, associated with anthropogenic nitrogen inputs, is a global reality. Opportunistic green macroalgae, other bloom species and species susceptible to growing nitrogen concentration, can be rapidly affected by ammonium and nitrate availability altering ecological dynamics of both populations and communities.

Nitrate reductase, through being the first enzyme in the nitrogen assimilatory pathway, assumes the responsibility for controlling the nitrate assimilatory rate in all algal cells. Thus, due to its importance in the general metabolism connected to $\mathrm{N}$ and $\mathrm{C}$ pathways, there is a constantly growing interest in studying the molecular and catalytic properties of NR enzymes and physiological responses to environmental stressing conditions and intracellular factors.

Previous studies on NR activity in micro and macroalgae, encountered the contradiction of using assay protocols without optimization, thus making comparison difficult, with little emphasis being placed on appropriate NR extraction and assaying. Nitrate reductase, through being a sensitive enzyme, rapidly inducible and repressive at various molecular levels and with diverse internal and external factors, is important for establishing minimum optimal conditions, both for comparison and acquiring an understanding of nitrogen metabolism. 
The constant accumulation of knowledge on NR activities, together with studies of nutrient uptake, will facilitate the collection of tools for: (1) identifying limiting, defective and saturating levels of growth-nutrients; (2) regulating pathways of nitrogen assimilation and incorporation; (3) providing environmental indicators for monitoring; (4) identifying macroalgae with high nitrate-reduction potential for biofilter application in eutrophized environments and increasing the standing crop in polycultures; (5) optimizing culture systems by regulating the reduction rate of nitrate with optimal nitrogen uptake and reduction; (6) developing management strategies for the culture of economically important algae; and (7) understanding evolutive patterns that support the adaptation of macroalgae to their environment.

Further studies of NR activity, both in the field and laboratory, are necessary as a contribution, both to understanding seaweed physiology, as well as to clarify the importance and role of these algae in near-shore biogeochemical cycling. Moreover, the constant changes in the coastal environment, brought about by anthropic action (artificial eutrophication), and variations arising from global climate change, will undoubtedly influence the ranges of tolerance and acclimation of algae, whereby the necessity for monitoring changes in coastal environments and communities.

\section{Acknowledgment}

The author would thank the research financial support of São Paulo Research Foundation (FAPESP).

\section{References}

Balandin, T. \& Aparicio, P. J. (1992). Regulation of nitrate reductase in Acetabularia mediterranea. J. Exp. Bot. 43:625-631.

Berges, J.A. (1997). Algal nitrate reductases. Eur. J. Phycol. 32: 3-8.

Berges, J. A. \& Harrison, P. J. (1995). Nitrate reductase activity quantitatively predicts the rate of nitrate incorporation under steady state light limitation: a revised assay and characterization of the enzyme in three species of marine phytoplankton. Limnol. Oceanogr. 40: 82-93.

Berges, J. A., Cochlan, W. P. \& Harrison, P. J. (1995). Laboratory and field responses of algal nitrate reductase to diel periodicity in irradiance, nitrate exhaustion, and the presence of ammonium. Mar. Ecol. Prog. Ser. 124: 259-269.

Berges J.A.,Varela D.E. \& Harrison P.J. (2002) Effects of temperature on growth rate, cell composition and nitrogen metabolism in the marine diatom Thalassiosira pseudonana (Bacillariophyceae). Marine Ecology Progress Series 225, 139-146.

Brinkhuis, B. H.; Renzhi, L.; Chaoyuan, W. \& Xun-sen, J. (1989). Nitrite reductase transients and consequences for in vivo algal nitrate reductase assays. J. Phycol. 25: 539-45.

Cabello-Pasini, A.; Macías-Carranza, V.; Abdala, R.; Korbee, N. \& Figueroa, F. L. (2011). Effect of nitrate concentration and UVR on photosynthesis, respiration, nitrate reductase activity, and phenolic compounds in Ulva rigida (Chlorophyta). J. Appl. Phycol. 23: 363-369.

Campbell, W. H. (1996). Nitrate reductase biochemistry comes of age. Plant Physiol. 111: 355-361. 
Campbell, W. H. (1999). Nitrate reductase structure, function, and regulation: bridging the gap between biochemistry and physiology. Annu. Rev. Plant Physiol. Plant Mol. Biol. 50: 277-303.

Chapman, D.J. \& P.J. Harrison. 1988. Experiment 22. Nitrogen metabolism and measurement of nitrate reductase. In: Experimental Phycology. A Laboratory Manual. Lobban, C.S., D.J. Chapman \& B.P. Kremer (eds). Cambridge University Press, Cambridge, USA. Pp. 196-202.

Chow, F. \& Oliveira, M. (2008). Rapid and slow modulation of nitrate reductase activity in the red macroalga Gracilaria chilensis (Gracilariales, Rhodophyta): influence of different nitrogen sources. J. Appl. Phycol. 20: 775-782.

Chow, F.; Oliveira, M. C. \& Pedersén, M. (2004). In vitro assay and light regulation of nitrate reductase in the red alga Gracilaria chilensis. J. Plant Physiol. 161: 769-776.

Chow, F.; Capociama, F. V.; Faria, R. \& Oliveira, M. C. (2007). Characterization of nitrate reductase activity in vitro in Gracilaria caudata J. Agardh (Rhodophyta, Gracilariales). Rev. Brasil. Bot. 30: 123-129.

Chow, F.; Macchiavello, J.; Santa-Cruz, S.; Fonck, E. \& Olivares, J. (2001). Utilization of Gracilaria chilensis (Rhodophyta, Gracilariaceae) as a biofilter in the depuration of effluents from tank cultures of fish, oysters, and sea urchins. J. World Aquacul. Soc. 32: 215-20.

Collén, J. \& Davison, I. R. (2001). Seasonality and thermal acclimation of reactive oxygen metabolism in Fucus vesiculosus (Phaeophyceae). J. Phycol. 37: 474-481.

Collos, Y. (1989). A linear model of external interactions during uptake of different forms of inorganic nitrogen by microalgae. J. Plankton. Res. 11: 521-523.

Corzo, A. \& Niell, F. X. (1991). Determination of nitrate reductase activity in Ulva rigida C. Agardh by the in situ method. J. Exp. Mar. Biol. Ecol. 146: 181-191.

Crawford, N. M. (1995). Nitrate-nutrient and signal for plant growth. Plant Cell 7: 859-868.

Crawford, N. M. \& Arst, H. N., Jr. (1993). The molecular genetics of nitrate assimilation in fungi and plants. Ann. Rev. Genet. 27: 115-46.

Davison I.R. \& Davison J.O. (1987) The effect of growth temperature on enzyme activities in the brown alga Laminaria saccharina. British Phycol. J. 22: 77-87.

Davison I.R. \& Stewart W.D.P. (1984) Studies on nitrate reductase activity in Laminaria digitata (Huds.) Lamour. II. The role of nitrate availability in the regulation of enzyme activity. J. Exp. Mar. Biol. Ecol. 79: 65-78.

Davison I.R., Andrews M. \& Stewart W.D.P. (1984) Regulation of growth in Laminaria digitata: use of in vivo nitrate reductase activities as an indicator of nitrogen limitation in field populations of Laminaria spp. Mar. Biol. 84: 207-217.

Davison, I.; Jordan, T.; Fegley, J. \& Grobe, C. (2007). Response of Laminaria saccharina (Phaeophyta) growth and photosynthesis to simultaneous ultraviolet radiation and nitrogen limitation. J. Phycol. 43: 636-646.

DeBoer, J.A. (1981). Nutrients. In: Lobban, C. S. \& Wynne, M. J. (eds.). The Biology of Seaweeds, Bot. Monogr., pp. 356-392.

Deng, M.-D.; Moureaux, T.; Cherel, I.; Boutin, J.-P. \& Caboche, M. (1991). Effects of nitrogen metabolites on the regulation and circadian expression of tobacco nitrate reductase. Plant Physiol. Biochem. 29: 239-247. 
Eppley, J.; Coastworth, L. \& Solorzado, L. (1969). Studies of nitrate reductase in marine phytoplankton. Limnol. Oceanogr. 14: 194-205.

Falkowski, P. G. (1992). Molecular ecology of phytoplankton photosynthesis. In: Falkowski, P. G. \& Woodhead, A. (eds.). Primary Productivity and Biogeochemical Cycles in the Sea, pp. 47-67. Plenum Press, New York.

Falkowski, P. G. \& Raven, J. A. (1997). Aquatic Photosynthesis. Blackwell Science, UK. 375 pp.

Fernández-López, M.; Olivares, J. \& Bedmar, E. J. (1996). Purification and characterization of the membrane-bound nitrate reductase isoenzymes of Bradyrhizobium japonicum. FEBS Lett. 392: 1-5.

Figueroa, F.L. \& Viñegla, B. (2001). Effects of solar radiation on photosynthesis and enzyme activities (carbonic anhydrase and nitrate reductase) in marine macroalgae from southern Spain. Rev. Chil. Hist. Nat. 74: 237-249.

Flynn, K. J. 1991. Algal carbon-nitrogen metabolism: a biochemical basis for modeling the interactions between nitrate and ammonium uptake. J. Plankton Res. 13: 373-387.

Gao, Y.; Smith, G. J. \& Alberte, R. S. (1993). Nitrate reductase from the marine diatom Skeletonema costatum biochemical and immunological characterization. Plant Physiol. 103: 1437-1445.

Gao Y., Smith G.J. \& Alberte R.S. (1995) Induction of nitrate reductase activity by light and $\mathrm{NO}_{3}$ - in the marine diatom Skeletonema costatum. Plant Physiol. 108: 71.

Gao Y., Smith G.J. \& Alberte R.S. (2000) Temperature dependence of nitrate reductase activity in marine phytoplankton: biochemical analysis and ecological, implications. J. Phycol. 36: 304-313.

Gao, Y.; Smith, G. J. \& Alberte, R. S. (1992). Light regulation of nitrate reductase in Ulva fenestrata (Chlorophyceae). I. Influence of light regimes on nitrate reductase activity. Mar. Biol. 112: 691-696.

Glaab, J. \& Kaiser, W. M. (1996). The protein kinase, protein phosphatase and inhibitor protein of nitrate redutase are ubiquitous in higher plants and independent of nitrate reductase turnover. Planta 199: 57-63.

Gordillo, F. J. L.; Aguilera, J. \& Jiménez, C (2006). The response of nutrient assimilation and biochemical composition of Arctic seaweeds to a nutrient input in summer. J. Exp. Bot. 57: 2661-2671.

Granbom, M.; Pedersén, M.; Kadel, P. \& Lüning, K. (2001). Circadian rhythm of photosynthesis in the red macroalga Kappaphycus alvarezii: dependence on light quantity and quality. J. Phycol. 37: 1020-1025.

Granbom, M.; Chow, F.; Lopes, P. F.; Oliveira, M. C.; Colepicolo, P.; Paula, J. P. \& Pedersén, M. (2004). Characterisation of nitrate reductase in the marine macroalga Kappaphycus alvarezii (Rhodophyta). Aquat. Bot. 78: 295-305.

Granbom, M.; Lopes, P. F.; Pedersén, M. \& Colepicolo, P. (2007). Nitrate reductase in the marine macroalga Kappaphycus alvarezii (Rhodophyta): oscillation due to the protein level. Bot. Mar. 50: 106-112.

Hanisak, M. D. (1983). The nitrogen relationships of marine macroalgae. In: Carpenter, E. J. \& Capone, D. G. (eds.). Nitrogen in the Marine Environment. Academic Press, New York, pp. 699-730. 
Hernández I., Corzo A., Gordillo F.J., Robles M.D., Saez E., Fernández J.A. \& Niell F.X. (1993). Seasonal cycle of the gametophytic form of Porphyra umbilicalis - nitrogen and carbon. Mar. Ecol. Progress Ser. 99: 301-311.

Howartha, D. G. \& Baumb, D. A. (2002). Phylogenetic utility of a nuclear intron from nitrate reductase for the study of closely related plant species. Molec. Phylog. Evol. 23: 525-528.

Huber, J. L.; Huber, S. C.; Campbell, W. H. \& Redinbaugh, M. G. (1992a). Reversible light/dark modulation of spinach leaf nitrate reductase activity involves protein phosphorylation. Arch. Biochem. Biophys. 296: 58-65.

Huber, J. L.; Huber, S. C.; Campbell, W. H. \& Redinbaugh, M. G. (1992b). Reversible light dark modulation of spinach leaf nitrate reductase-activity involves proteinphosphorylation. Arch. Biochem. Biophys. 296: 58-65.

Huovinen, P.; Matos, J.; Sousa-Pinto, I. \& Figueroa, F. (2006). The role of nitrogen in photoprotection against high irradiance in the Mediterranean red alga Grateloupia lanceola. Aquat. Bot. 84: 208-316.

Hurd, C. L.; Berges, J. A.; Osborne, J. \& Harrison, P. J. (1995). An in vitro nitrate reductase assay for marine macroalgae: optimization and characterization of the enzyme for Fucus gardneri (Phaeophyta). J. Phycol. 31: 835-43.

Kain, J. M. (1989). The seasons in the subtidal. Br. Phycol. J. 24: 203-215.

Kaiser, W. \& Huber, S. C. (1994). Posttranslational regulation of nitrate reductase in higher plants. Plant Physiol. 106: 817-821.

Kaiser, W. M. \& Spill, D. (1991). Rapid modulation of spinach leaf nitrate reductase by photosynthesis. II. In vitro modulation by ATP and AMP. Plant Physiol. 96: 368-375.

Korbee-Peinado, N.; Abdala-Díaz, R.; Figueroa, F. \& Helbling, W. (2004). Ammonium and UV radiation stimulate the accumulation of mycosporine-like amino acids in Porphyra columbina (Rhodophyta) from Patagonia, Argentina. J. Phycol. 40: 248259.

Lapointe, B. E. \& Duke, C. S. (1984). Biochemical strategies for growth of Gracilaria tikvahiae (Rhodophyta) in relation to light intensity and nitrogen availability. J. Phycol. 20: 488-495.

Lartigue J. \& Sherman T.D. (2002) Field assays for measuring nitrate reductase activity in Entermorpha sp. (Chlorophyceae), Ulva sp. (Chlorophyceae) and Gelidium sp. (Rhodophyceae). J. Phycol. 38: 971-982.

Lartigue J. \& Sherman T.D. (2005) Response of Enteromorpha sp. (Chlorophyceae) to a nitrate pulse: nitrate uptake, inorganic nitrogen storage, and nitrate reductase activity. Mar. Ecol. Progress Ser. 292: 147-157.

Lillo, C. (1983). Studies of diurnal variations of nitrate reductase activity in barley leaves using various assay methods. Physiol. Plant. 57: 357-362.

Lillo, C. (1994). Light regulation of nitrate reductase in green leaves of higher plants. Physiol. Plant. 90: 616-620.

Lobban, C. S. \& Harrison, P. J. (1994). Seaweed Ecology and Physiology. Cambridge University Press, Cambridge. 366 pp.

Lobban, C. S.; Harrison, P. J. \& Duncan, M. J. (1985). The physiological ecology of seaweeds. Cambridge University Press, Cambridge. 
Lopes P.F., Oliveira M.C. \& Colepicolo P. (1997). Diurnal fluctuation of nitrate reductase activity in the marine red alga. J. Phycol. 33: 225-231.

Lopes, P. F.; Oliveira, M. C. \& Colepicolo P. (2002). Characterization and daily variation of nitrate reductase in Gracilaria tenuistipitata (Rhodophyta). Biochem. Biophys. Res. Commun. 295: 50-54

MacKintosh, C.; Douglas, P. \& Lillo, C. (1995). Identification of a protein that inhibits the phosphorylated form of nitrate reductase from spinach (Spinacia oleracea) leaves. Plant Physiol. 107: 451-457.

Martins, A. P., Chow, F. \& Yokoya, N. S. (2009). Ensaio in vitro da enzima nitrato redutase e efeito da disponibilidade de nitrato e fosfato em variantes pigmentares de Hypnea musciformis (Wulfen) J.V. Lamour. (Gigartinales, Rhodophyta). Rev. Brasil. Bot. 32: 635-645.

Nakamura, Y. \& Ikawa, T. (1993). Purification and properties of NADH: nitrate reductase from red alga Pophyra yezoensis. Plant Cell Physiol. 34: 1239-49.

Nakamura, Y., Saji, H., Kondo, N. \& Ikawa, T. (1994). Preparation of monoclonal antibodies against NADH-nitrate reductase from the red alga Porphyra yezoensis. Plant Cell Physiol. 35: 1185-1198.

Nicodemus, M. A.; Salifu, K. F. \& Jacobs, D. F. (2008). Nitrate reductase activity and nitrogen compounds in xylem exudate of Juglans nigra seedlings: relation to nitrogen source and supply. Trees Struct. Funct. 22: 685-695.

Ramalho, C. B., Hastings, J. W. \& Colepicolo. P. (1995). Circadian oscillation of nitrate reductase activity in Gonyaulax polyedra. Plant Physiol. 107: 225-231.

Smith, G. J.; Zimmerman, R. C. \& Alberte, R. S. (1992). Molecular and physiological responses of diatoms to variable levels of irradiance and nitrogen availability: growth of Skeletonema costatum in simulated upwelling conditions. Limnol. Oceanogr. 37: 989-1007.

Solomonson, L. P. \& Barber, M. J. (1990). Assimilatory nitrate reductase: functional properties and regulation. Annu. Rev. Plant Physiol. Plant Mol. Biol. 41: 225-253.

Stolz, J. F. \& Basu, P. (2002). Evolution of nitrate reductase: molecular and structural variations on a common function. Chem. BioChem. 3: 198-206.

Thomas, T. E. \& Harrison, P. J. (1988). A comparison of in vitro and in vivo nitrate reductase assays in three intertidal seaweeds. Bot. Mar. 31: 101-107.

Tischner, R.; Ward, M. R. \& Huffaker, R. C. (1989). Evidence for a plasma-membrane-bound nitrate reductase involved in nitrate uptake of Chlorella sorokiniana. Planta 178: 1924.

Vergara, J. J.; Berges, J .A. \& Falkowski, P. G. (1998). Diel periodicity of nitrate reductase activity and protein levels in the marine diatom Thalassiosira weissflogii (Bacillariophyceae). J. Phycol. 34: 952-961.

Weidner, M.; \& Kiefer, H. (1981). Nitrate reduction in the marine brown algae Giffordia mitchellae (Harv.) Ham. Z. Pflazenphysiol. Bd. 104: 341-351.

Young, E. B., Dring, M. J., Savidge, G., Birkett, D. A \& Berges, J. A. (2007). Seasonal variations in nitrate reductase activity and internal $\mathrm{N}$ pools in intertidal brown algae are correlated with ambient nitrate concentrations. Plant, Cell and Environ. 30: 764-774. 
Young, E. B., Berges, J. A. \& Dring, M. J. (2009). Physiological responses of intertidal marine brown algae to nitrogen deprivation and resupply of nitrate and ammonium. Physiol. Plant. 135: 400-411.

Zhou, J. \& Kleinhofs, A. (1996). Molecular evolution of nitrate reductase genes. J. Mol. Evol. 42: 432-442. 


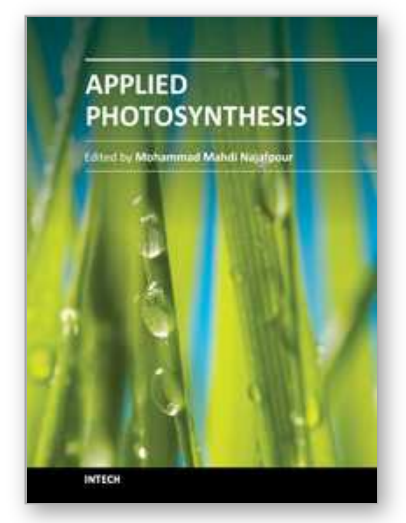

\author{
Applied Photosynthesis \\ Edited by Dr Mohammad Najafpour
}

ISBN 978-953-51-0061-4

Hard cover, 422 pages

Publisher InTech

Published online 02, March, 2012

Published in print edition March, 2012

Photosynthesis is one of the most important reactions on Earth, and it is a scientific field that is intrinsically interdisciplinary, with many research groups examining it. This book is aimed at providing applied aspects of photosynthesis. Different research groups have collected their valuable results from the study of this interesting process. In this book, there are two sections: Fundamental and Applied aspects. All sections have been written by experts in their fields. The book chapters present different and new subjects, from photosynthetic inhibitors, to interaction between flowering initiation and photosynthesis.

\title{
How to reference
}

In order to correctly reference this scholarly work, feel free to copy and paste the following:

Fungyi Chow (2012). Nitrate Assimilation: The Role of In Vitro Nitrate Reductase Assay as Nutritional Predictor, Applied Photosynthesis, Dr Mohammad Najafpour (Ed.), ISBN: 978-953-51-0061-4, InTech, Available from: http://www.intechopen.com/books/applied-photosynthesis/nitrate-assimilation-the-role-of-invitro-nitrate-reductase-assay-as-nutritional-predictor

\section{INTECH}

open science | open minds

\section{InTech Europe}

University Campus STeP Ri

Slavka Krautzeka 83/A

51000 Rijeka, Croatia

Phone: +385 (51) 770447

Fax: +385 (51) 686166

www.intechopen.com

\section{InTech China}

Unit 405, Office Block, Hotel Equatorial Shanghai

No.65, Yan An Road (West), Shanghai, 200040, China

中国上海市延安西路65号上海国际贵都大饭店办公楼 405 单元

Phone: +86-21-62489820

Fax: $+86-21-62489821$ 
(C) 2012 The Author(s). Licensee IntechOpen. This is an open access article distributed under the terms of the Creative Commons Attribution 3.0 License, which permits unrestricted use, distribution, and reproduction in any medium, provided the original work is properly cited. 